\title{
“Периферийное знание” в дискурсе креативности: социальные сети интересного
}

\author{
К.В. Сергеев
}

Сергеев Кирилл Викторович, стажер-исследователь Института истории естествознания и техники РАН.

Самое лучшее в новом - то, что отвечает старому устремлению.

Поль Валери

Один из наиболее серьезных вопросов, стоящих ныне перед общественными науками, — природа социальных трансформаций. Каким образом устойчивая социальная структура оказывается подверженной изменениям, коренящимся в ее же собственной природе? Будучи феноменом социального пространства, такие трансформации имеют сугубо когнитивную природу, ибо инновации являются следствиями креативных процессов, в которые вовлекается некая совокупность субъектов общества. Чтобы приблизиться к пониманию логики трансформации последнего, необходимо вначале “морфологически” описать данную совокупность. Но прежде мы должны выделить те когнитивные основания, которые ее формируют и позволяют обеспечить ее субъектам необходимый для инновационной деятельности креативный потенциал.

Итак, проанализируем ситуацию социальной трансформации. Общественному пространству, как и пространству биологическому, принципиально чужда статика. Социум постоянно пребывает в состоянии развития. И даже оставаясь стабильным, он неуклонно эволюционирует, его институциональный дизайн совершенствуется, возникают новые структуры, способные адекватно отвечать на те вызовы, которые исходят от окружающего мира. “Покоясь в изменении”, социум обновляет свои формы так же, как обновляет себя живой организм, чьи клетки, умирая, сменяются новыми, или как биологический вид, сохраняющий свое единство и “видовой опыт” со смертью особей, к нему принадлежащих [Кузин 1992]. Если же общественное пространство охватывает кризис, то процесс обновления его структур неимоверно ускоряется, более того - происходит нарушение естественного хода эволюции социальных форм. И тогда инновационные процессы уподобляются механизмам биологической мутации, позволяющей сохранить жизненно важные функции организма ценой морфологических изменений, иногда весьма значительных.

Перманентное “становление” социума — явление абсолютно очевидное для сколько-нибудь наблюдательного человека. Вместе с тем эта очевидность скрывает за собой естественный, хотя и весьма непростой вопрос: а чем, собственно, обеспечивается непрерывное развитие социума, в результате которого социальное знание не утрачивается, но накапливается, а общественная структура самовоспроизводится без “морфологических дефектов”? На самых нижних уровнях - биологическом и этологическом — ответ очевиден: самовоспроизводство homo sapiens гарантируется стабильным числом потенциальных социальных субъектов, в то время как этологический императив подталкивает их к обретению первичных социальных форм [Morris 1967]. Затем, по мере накопления опыта внутренних взаимодействий, вырабатываются определенные “правила игры”, возникают социальные институты и сетевые сообщества. И поскольку “приобретенные” признаки не наследуются биологическим образом, когнитивный и социальный опыт передается иным путем, а именно через обучение, социализирующее субъект и вписывающее его в рамки когнитивного опыта данного социума.

Какого рода знание необходимо для социализации, т.е. для приобретения социокультурного опыта, и какого рода способности должны в результате раскрыться у субъекта обучения? На этот вопрос различные типы социума дают совершенно разные ответы. Попробуем их типологизировать. Древнейший тип социализирующего знания - знание о “формальных принципах” взаимодействия универсума, социума и индивида. Знание это можно условно назвать магическим, ибо в рамках такой когнитивной модели и универсум, и социум, и индивид в равной степени подчинены универсальным законам и правилам, и при их соблюдении ни с социальным субъектом, ни с социумом в целом не может случиться “ничего дурного”: мир предстает абсолютно рациональным, “механистичным”, а попросту говоря — тотально ритуализированным. Знание ритуала и умение это знание применить и выступает в данном случае условием социализации. 
Следующий тип социализирующего знания - знание о внутренних возможностях человека, не поддающихся рефлексии, но реализуемых через специфическую духовную практику. С первого взгляда может показаться, что подобное знание асоциально, однако это не так. При такой когнитивной модели мир оказывается поделен на две сферы - сферу внутреннего, духовного опыта и сферу внешнюю, чисто социальную и одновременно “профанную”. Вторая область существует как “тень”, как бледное, искаженное отражение первой, и потому знания, относящиеся к этой первой, являются и знаниями о социальном мире. В основе рассматриваемой модели лежит идея тождественности микрокосма и макрокосма, так что, познавая себя, человек познает и социальную реальность, и реальность высшего порядка.

Наконец, третий тип социализирующего знания есть знание о механизмах рефлексии, позволяющее не только понимать чужой опыт, но и интерпретировать любую нетривиальную ситуацию. Здесь необходимо сказать несколько слов о соотношении рефлексии и опыта. Опыт, как известно, не сводим к формальному, фактологическому знанию. Он представляет собой обладание знанием о правилах, которые дают возможность выбрать верную модель действий в нетрадиционной ситуации (при том что такие правила “тестируются” через соприкосновение с новой, “непонятной” ситуацией). Иными словами, опыт — это тот капитал, без которого немыслима инновационная деятельность. Рефлексия позволяет создать в сознании соответствующего субъекта “виртуальный опыт”, т.е. смоделировать когнитивную схему допустимых ситуаций определенного рода и тем самым заместить опыт практического “пребывания в ситуации” опытом мышления.

В этом свете становится очевидным, что рефлексия как механизм социализации в несопоставимо большей степени способствует рождению социальных инноваций, нежели механизмы первых двух типов. В традиционном, стабильном обществе знание ритуала - залог воспроизводства социальных институтов, но в ситуации кризиса ритуальная практика оказывается бессильной, ибо “логика универсума” меняется и социальные субъекты уже не могут найти в своем общественном опыте способ стабилизации. В качестве примера можно привести кризис архаического полиса в Греции, приведший к полному забвению социального и когнитивного опыта доклассической эпохи [Andrews 1962; Harrison 1989, 1991; Osborne 1996]. Более устойчивы к кризисам те общества, где механизмом социализации выступает интуитивное самопознание, однако это достигается ценой потери единства социума, чьи субъекты атомизируются, будучи в состоянии стабилизировать лишь свой собственный внутренний мир, но не обеспечить быструю регенерацию социального тела. Примером тому служит история Китая: несмотря на многократные нашествия “варваров”, тот не утрачивал своей культуры, т.е. социального и когнитивного опыта, но надолго лишался социального единства, распадаясь на небольшие сетевые сообщества [Васильев 1972].

Классическим и исключительно “успешным” образцом социума, где механизмом социализации выступала рефлексия, было европейское общество эпохи Модерна. Не случайно в процессе всемирной глобализации именно эта модель оказалась доминирующей [North, Thomas 1982; Habermas 1987; Toulmin 1990; Giddens 1991]. Стремительная эволюция европейского общества за последние четыреста лет, вопреки чудовищным социальным и когнитивным кризисам конца XVIII - XX в., свидетельствует о том, что в недрах его существует мощный инновационный потенциал, способный актуализироваться и адекватно отвечать на “вызовы истории” — как гибкой институциональной трансформацией, так и раздвижением “когнитивных горизонтов”.

У внимательного наблюдателя, однако, не может не возникнуть вопрос: а каковы практические механизмы социализации обучающегося субъекта через рефлексию, как рефлексия “инсталлируется” в сознание человека? Чтобы ответить на него, необходимо вначале хотя бы грубо очертить пути привнесения знаний в человеческий разум.

Конечно, таких путей настолько много, что любая попытка полно их описать была бы не чем иным, как пагубной самонадеянностью. Тем не менее, мы вправе с уверенностью говорить о наличии двух принципиально разных способов обретения нового знания: в одном случае человек приобретает его сознательно, по доброй воле, следуя своей внутренней логике, в другом - знание транслируется благодаря искусственно созданным ситуациям, привитым моделям поведения, апелляции к инстинктам и чувствам. Во втором случае речь идет о моделях обучения индивида, приводящих к его социализации. В разных социокультурных общностях эти модели далеко не одинаковы, и даже в пределах одной культуры зачастую используются взаимоисключающие подходы - репрессивные, “естественные”, “когнитивные”. Рассмотрим их вкратце на примере европейского общества. 
В рамках репрессивного подхода, апеллирующего к этологическим основаниям человека, обучение трактуется как исправление или обуздание индивида с целью его максимально успешной социализации. Начиная с эпохи Модерна указанный способ обучения уже не являлся доминирующим, но его отголоски прослеживаются еще у педагогов-теоретиков XIX в. [Гербарт 1940]. Практику репрессивной социализации индивида блестяще описал М.Фуко, проанализировавший такие “институты воспитания”, как тюрьма и сумасшедший дом [Фуко 1997, 2000].

\begin{abstract}
“Естественные” модели, ориентирующиеся на природные задатки субъекта и восходящие к идее “естественного человека” Ж.Ж. Руссо [Руссо 1969], приобрели наибольшую популярность в ХІХ в., найдя свое воплощение в педагогической практике [Песталоцци 1981]. Согласно этим моделям, гармоничное развитие субъекта обучения есть взращивание природных начал и предрасположенностей, “помощь природе”. Интересно отметить, что сторонники “естественных” моделей социализации видели в них средство развития у человека этических принципов как основы его личности. В этом смысле задачей социализации было формирование специфической “гражданской” системы ценностей, а знание выступало инструментом создания последней.

“Когнитивные” методы нацелены на развитие и совершенствование механизмов рефлексии субъекта обучения и пробуждение в нем креативности [Вертгеймер 1987]. Несмотря на безусловную привлекательность этих методов, существует ряд проблем с их применением в “реальной”, т.е. массовой, практике социализации. Во-первых, очевидно, что субъекты обучения обладают неодинаковым интеллектуальным, а точнее - интерпретационным потенциалом (правильнее сказать, их потенциал способен реализоваться в различных, подчас диаметрально противоположных видах деятельности) и что излишнее усложнение, или спецификация, методов обучения приведет к резкому разделению обучаемых на тех, чья креативность начинает реализовываться, и тех, кто в силу специфичности обучения окажется “неспособным” к развитию рефлексии. С другой стороны, процесс внедрения в сознание обучаемого механизмов креативности столь сложен и требует от обучающего таких интеллектуальных усилий, что “когнитивные” методы социализации едва ли станут доминирующими.
\end{abstract}

Вместе с тем имеется когнитивный метод, чья эффективность настолько высока, что может создать у субъекта обучения внутреннюю потребность к поиску нового знания, к инновационной деятельности, тем самым резко снизив трансакционные издержки социализации. Метод этот состоит в пробуждении в субъекте обучения чувства интересного. Сразу же следует оговорить, что пробуждение чувства интересного не равнозначно выработке интереса к некоему предмету [см. Голосовкер 1989]: в первом случае происходит полифоническое развитие когнитивных потенций субъекта обучения, во втором - узкая

профессионализация как результат весьма ограниченного опыта рефлексии. Иными словами, в одном случае речь идет о способности субъекта самостоятельно подвергать рефлексии множество разнообразных явлений, исходя из ощущения их системного единства, в другом - о чем-то привитом извне.
Человек редко задумывается над тем, что существует в его сознании как данность, как изначальный постулат, естественный инструмент осмысления окружающей его реальности. Рефлексия в состоянии с легкостью охватывать лишь неустоявшееся, загадочное, неукорененное, т.е. не нашедшее себе место в строгой иерархии мысленных ценностей, которую человек получает в наследство от окружающего его мира в момент первичного усвоения знания, первичной социализации. Плоды чужой рефлексии - мертвое наследство. Мертвое не может пробудить интерес, но способно отяготить его, сделав взгляд человека на мир более тяжеловесным. Таким образом, в сознании человека “чужие”, непостигаемые механизмы интерпретации реальности противостоят механизмам, самостоятельно приобретаемым по мере развития в нем чувства интересного.

Взаимопроникновение данных механизмов происходит в процессе социализации, когда человек, усваивая отобранную, утвержденную и апробированную сумму обязательного знания, одновременно учится самостоятельно мыслить, выискивая в существующем знании то, что ему представляется индивидуально интересным и полезным. Два потока знания встречаются, и обязательное, “фундаментальное” знание создает скелет, обрастающий “периферийным” знанием, хаотично возникшим под действием чувства интересного. Но так ли это? Встает неочевидный на первый взгляд вопрос: как реально соотносятся в сознании обучающегося субъекта “фундаментальное” и “периферийное” (т.е. “мертвый” внешний опыт и то знание, которое пробуждает в человеке креативность) и насколько едино первое и эклектично - второе?

Напрашивается и иной вопрос: а какова социальная проекция этих двух конкурирующих структур знания? 
Несомненно, что “фундаментальное” знание четко иерархизировано, ибо оно уже обрело “застывшую”, стандартную интерпретацию и вошло в совокупный социокультурный опыт, заняв там некое фиксированное место. “Периферийное” знание, наоборот, полностью принадлежит креативной, инновационной сфере; оно лишь стремится войти в совокупный опыт и, будучи апробировано лишь рефлексией, но не опытом, не может претендовать на определенное место в иерархии знания. Между тем “периферийному” знанию нельзя отказать в целостности: подобно “фундаментальному”, оно тоже структурировано, но не иерархическим, а сетевым образом. Мы можем предположить, что социальными проекциями обсуждаемых типов знания (т.е. теми социальными формами, которые структурируют носителей “фундаментального” знания и производителей знания “периферийного”) будут в первом случае социальная иерархия и сеть интересного во втором.

Мы подошли к исключительно важной проблеме: каким образом структурируются институты, призванные инициировать у субъектов креативность для продуцирования когнитивных и социальных инноваций? Но чтобы непосредственно приступить к рассмотрению сетей интересного и понять, какова логика “периферийного” знания, нужно проанализировать то, что пробуждает это знание, а именно — возникающее в человеке чувство интересного.

Интересное - надтривиально. Очевидность (то, что само собой разумеется) не может быть интересной. Интересно ускользающее, неустоявшееся, подвижное, освобождающее мысль человека. Окружающая нас реальность разделена по принципам: тривиально — нетривиально, осознанно - неосознанно, загадочно очевидно. Очевидность - не что иное, как подобие сот, куда помещается каждый осознанный человеком мысленный объект; оказавшись там, он лишается свободы, становясь частью единой конструкции, занимая фиксированное, отведенное ему место. Интересное же обладает свободой, и эта свобода (невключенность в общую иерархию) делает объект интересным.

Интересное - это вопрос. Любая догма или кажущаяся самоочевидность сокращает пространство интересного, но если возникает вопрос: почему нечто не самоочевидно, необъяснимо с точки зрения имеющихся тривиальных представлений, то оно уже интересно. Вопрос и последующий ответ на него превращают интересное в тривиальное, осознанное, но оно, будучи осознано самостоятельно, запускает в человеке механизм рефлексии, волю к независимому осмыслению в противовес механистическому усвоению. Интересное пробуждает в человеке креативность.

Попробуем определить те границы, в которых существует интересное. Омертвелое знание очерчивает лишь нижний предел, проводя грань между понятым и всем немыслимым хаосом не обретших форму образов и идей, о которых человеку трудно даже помыслить. Но эта потенциальная материя мысли, “живая глина”, из которой машина рефлексии некогда будет лепить предметы, населяющие человеческое мышление, не может быть интересна в своем состоянии неоформившегося зародыша. Хаос, полная неупорядоченность, нелогичность не интересны так же, как не интересно тривиальное, разложенное по полочкам, анатомированное, мертвое. Иначе говоря, интересное сродни живописному холсту: оно нуждается в раме, отграничивающей его от хаотического мира и определяющей ему некое особое место между человеческой обыденностью и стихийной природой.

На что бы мы ни смотрели, мы не в силах полностью охватить предмет, в который упирается наш взгляд. Так, глядя со стороны на глиняный сосуд, мы видим лишь его стенки, не имея возможности с того же ракурса заглянуть внутрь сосуда, а тем более различить бесконечное количество структур и частиц, из которых состоит глина. Глядя на уходящую на многие километры вдаль горную гряду, мы не в состоянии объять ее целиком, но видим лишь тот ее фрагмент, который попадает в фокус нашего глаза. Рефлексия, подобно глазу, содержит в себе некое подобие рамы, а правильнее сказать — интерпретационную модель; благодаря этой модели она охватывает лишь определенные аспекты интересующей нас реальности, не позволяя хаосу мельчайших элементов и беспредельных просторов затопить наше воображение. И в то же время указанная модель автоматически воссоздает в сознании человека объект целиком, в его общем виде, в его мельчайших деталях, с учетом всех свойств и особенностей. Хаос предикатов обретает логический классификатор.

Интересному, как и человеческому глазу, необходима объяснительная модель, и она возникает, едва мы начинаем оперировать множественными объектами, требующими строгой дифференциации и осмысления. 
Но появляющаяся модель не универсальна — каждая из “разновидностей” интересного нуждается в своем особом классификаторе объектов, позволяющем извлечь из хаоса именно те их особенности, которые представляют ценность в данной, конкретной системе интересного. Таким образом, попытка построения типологии объяснительных моделей оказывается тождественной типологизации интересного.

Интересное как редкое. Первый тип объяснительной модели - это классификатор, который рассматривает объекты, исходя из их зримых, внешних свойств; объект не расчленяется на структуры, но понимается как единое целое в пределах универсальной, заданной логики. Понятно, что большинство ячеек подобной классификационной сетки заполняются быстро, некоторые же - крайне медленно. Так образуется представление о редких объектах, интерес и ценность которых заключены в их труднонаходимости. К данной категории относятся, скажем, золото и алмазы, чья привлекательность для накопления объясняется не столько их полезными свойствами, сколько редкостью.

Рассматриваемая классификационная сетка бесконечно расширяема; любой объект с легкостью укладывается в оппозицию частое - редкое, не порождая у человека вопроса о природе своей редкости. Например, из внешних свойств золота (желтизны и мягкости) ни в коей мере ни следует, что все объекты, имеющие подобные свойства, будут столь же редкими. Интересное здесь не выходит за пределы понятия редкости, порождая бесконечные каталоги и стремление к поиску уникумов или объектов, обладающих редкими свойствами.

Интересное как редкое порождает коллекционирование; людей, разделяющих данную интерпретацию интересного, охватывает страсть к поиску предметов, вся ценность которых заключена в уникальности: хранители редкостей владеют тем, чем не владеет больше никто. При этом смысл объекта как бы уплощается, в фокусе зрачка остается лишь одно его свойство, ничего не говорящее о сущности предмета, но утверждающее его редкость в системе классификации. Указанный подход к природе интересного обнаруживается, например, в средневековых бестиариях, описывающих собакоголовых и трехногих обитателей далеких земель, якобы увиденных путешественниками; авторы классифицируют эти невообразимые создания не по структурному сходству (как позднее Линней классифицировал растения), но по степени их фантастичности, не задаваясь вопросом о природе той причудливой логики, по которой человек оказался наделен собачьей головой.

Таким образом, первый тип интересного не способен выработать у человека иную внутреннюю логику: редкость объекта не порождает вопроса о природе редкости, но лишь отграничивает тривиальное от интересного, очерчивая нижний рубеж непознанного.

Интересное как загадочное. Любой объект, помимо внешних признаков, обладает структурой, и чем сложнее объект, тем больше уровней имеет эта структура. Так, классифицируя структуры живого мира, человек уже не может использовать единую классификационную сетку, ибо периодически обнаруживаются объекты, разрушающие ее логику. Мы в состоянии в единой логической системе описать, к примеру, слона и волка, но пытаясь поместить в ту же систему муравья или осу, наталкиваемся на непреодолимое препятствие: если в первом случае организм тождественен особи, то во втором вся совокупность особей (муравейник или улей) представляет цельный организм, в котором отдельные живые существа выступают лишь элементами [Tinbergen 1942, 1953; Шовен 1956; Халифман 1963, 1964]. Сталкиваясь со столь странным феноменом, человек задается вопросом: что за логика породила этот объект, не вписывающийся в естественную, обыденную логику? Возникает необходимость в логическом совершенствовании самих классификаторов; интересным становится загадочное.

Попытки охватить возможные смыслы и логики приводят к “механизации” акта классификации. Человек старается изобрести механизм, классифицирующий все варианты структур, и действительно конструирует своеобразные логические машины — таковыми являются Ars Magna Р.Луллия и книга “И Цзин” (“Чжоу И”).

“И Цзин” стал базисным текстом китайской культуры - его логический механизм лег в основу китайского способа описания мира с присущими ему бесчисленными классификациями, каталогизациями, перечислениями [Щуцкий 1993]. Сама идея о том, что 64 гексаграммы, состоящие из шести чередующихся целых и разорванных черт, способны описать и охарактеризовать все проявления жизни, не могла не трансформировать сознание людей; мир для них превратился в бесконечную игру классификационных систем, в неисчислимую совокупность комбинаций, открывающих тайны всего непознанного и загадочного. 
“Великое искусство” Луллия, не получившее широкой известности в Европе, но оказавшее определенное (и, на наш взгляд, не до конца оцененное) влияние на развитие логической мысли, тоже стремилось каталогизировать объяснительные рамки, предложить некий механизм, который бы создавал новый классификатор для каждого объекта, не вмещающегося в существующую классификационную сетку [Bonner 1993]. Тем же самым занимались и средневековые каббалисты, а также иранские хуруфиты - с той лишь разницей, что логическую машину они видели не в магических дисках и гексаграммах, но в самом языке; особым образом проинтерпретированные комбинации букв в священных текстах вскрывали механизм осмысления объектов [Scholem 1969; Кули-Заде 1970].

Некоторые языки, например арабский и санскрит, в своем грамматическом строе фактически содержат универсальные классификаторы объектов и действий. Логическая структура санскрита была впервые вычленена пандитом Панини еще в V в. до н.э., что способствовало быстрому развитию логики в Индии. В арабском языке трехбуквенный согласный корень является логической основой, из которой с помощью добавления семантически нагруженных буквенных элементов строятся различные части речи, объединенные единым смысловым стержнем.

Итак, при анализе второго типа классификаторов мы обнаруживаем, что загадочное, будучи классифицированным, разрушает единую логику, замещая ее совокупностью новых логик, и вызывает у человека вопросы, касающиеся истинной природы тех структур, которые выпадают из сферы применения единого классификатора.

Интересное как система. Сталкиваясь с необъяснимым, человек впервые осознает в себе присутствие различных объяснительных систем. Возникнув, будучи осознанными, они вступают в его голове в удивительный полилог, то соединяясь в едином движении, то расходясь и образуя странный мысленный лабиринт. Этот полилог по своей структуре в чем-то сродни полифонической музыке, одновременно включающей несколько музыкальных тем, переплетающихся и создающих немыслимый, нечитаемый узор, возникающий откуда-то из потенциальных глубин и уходящий в неизвестность. Но несмотря на это кажущееся волшебство, хорошо известно, что музыкальная полифония строится по строгим математическим законам, многократно описанным в трактатах и пособиях. Чудом оказывается логика иного порядка.

Опираясь на этот пример как на живую метафору, мы вправе предположить, что существует не просто совокупность возможных логик, но единая система объяснительных схем, некая металогика. О ее законах мы еще не в состоянии сказать что-либо определенное, однако можем констатировать: она есть.

В начале XX в. П.Филонов выдвинул идею “аналитического искусства”, базирующегося на осознании всей совокупности элементов, воздействующих на зрителя. В своей “Декларации Мирового Расцвета” он писал: “Так как я знаю, анализирую, вижу, интуитирую, что в любом объекте не два предиката, цвет да форма, а целый мир видимых или невидимых явлений, их эманаций, реакций, включения, генезиса, бытия, известных или тайных свойств, имеющих иногда бесчисленные предикаты, то я отрицаю учение современного реализма ‘двух предикатов’ ... как ненаучное и мертвое - начисто” [Филонов 1923: 13]. В данном фрагменте художник фактически развивает мысль о том, что в живописи представляют интерес не две плоскости, но бесчисленное количество семантических плоскостей, создающих систему.

В результате перед нами возникает понятие интересного как системы. Творческое, всеобъемлющее проникновение вглубь предмета возможно лишь в том случае, если в фокусе глаза оказываются разом все грани, все срезы, все плоскости объекта, если объяснительная рамка, через которую объект воспринимается, в своей метаконструкции содержит все мыслимые объяснительные схемы; классификаторы обретают тогда внутреннюю гармонию, трансформируясь из атомизированной совокупности в сетевую систему, улавливающую все аспекты смыслов, все скрытые значения.

При создании такого метаклассификатора, такого небывалого оптического прибора разума единственной надежной опорой предстает метафорическая структура языка, самая подвижная, живая его часть, свободная от всего привнесенного, паразитического, мертвого. Если логический аспект языка в той или иной степени создан человеком и, в свою очередь, развивает в нем формальную логику, то метафорические структуры, так сказать, “самородны”, исконны, и их логика, существующая, но пока неуловимая, помогает человеку проникнуть в те структуры объекта, которые скрыты от него стеной формальной логики [Black 1962; Lakoff, Johnson, 1980; Кассирер 1990]. 
Метафоры, как и филоновские “живописные предикаты”, образуют некую суперструктуру, которую гораздо труднее различить невооруженным глазом, чем многоуровневость изображения на гравюрах Эшера, картинах последователей “аналитической школы живописи” и тибетских живописных свитках. Но если человек сумел проникнуть в эту систему интересного, для него исчезают иллюзорные междисциплинарные различия, и он может с одинаковой легкостью интерпретировать музыку и живопись, поэзию и философию, историю и социологию, вычленяя в них универсальные смысловые структуры. Собственно, таков “идеальный человек” Ренессанса и Барокко, будь то Дж.Б.Альберти или П.Учелло, С.Роза или Б.Марчелло [Sindona 1957; Salerno 1963; Gadol 1969]. Подобный человек словно бы собирает мозаику, воссоздавая в своем сознании некогда утерянное единство элементов мира и тем самым уменьшая пространство непознанного хаоса, наращивая живую ткань на скелет рефлексии.

И здесь вновь встает вопрос о реальном соотношении между “периферийным” знанием и “базисным”. Мы видим, что “периферийное”, свободное, неклишированное знание обладает гораздо большим единством, чем обычно представляется. Возникая в отдалении от базисного, скелетного знания, оно формирует в человеке систему интересного, иначе говоря - систему креативного мышления, расходящегося концентрическими кругами от “заброшенного” в сознание человека фундаментального знания и в то же время удерживающего его от тотальной иерархизации, способной подавить любые акты креативности.

“Фундаментальное”, иерархическое знание принципиально важно на первой ступени социализации, ибо оно создает в сознании обучающегося субъекта некую первичную объяснительную модель. Когда же возникает реальная необходимость инициировать рефлексию, “запустить” в человеке механизм креативности, периферийное знание оказывается той единственной основой, из которой формируется чувство интересного, способное вскоре перерасти в креативную способность.

Система интересного содержит в себе элементы того все еще загадочного механизма, той логики, благодаря которой новое знание пристыковывается к усвоенным базисным структурам сознания обучающегося субъекта и вслед за тем - эффективно аккумулируется. Не имея пока полноценного доступа к данной сфере, мы вынуждены довольствоваться лишь образными, метафорическими структурами, которые порождают в человеке мир интересного.

$* * *$

Теперь, рассмотрев систему интересного как чисто когнитивный феномен, мы можем перейти к анализу ее социальной проекции - сети интересного.

На наш взгляд, существуют некие “неформальные факторы”, которые, не вписываясь в институциональную историю социума, тем не менее выступают структурообразующими элементами инновационных процессов в обществе - как в условиях стабильности, так и в ситуации социального или когнитивного кризиса. К этим факторам относятся специфические взаимоотношения между субъектами различных социальных, этнических или культурных групп, способствующие поддержанию в социуме определенного потенциала креативности, который обеспечивает постоянные инновационные трансформации.

Но как определить, терминологизировать “неформальный фактор” социальной эволюции? С одной стороны, мы имеем традиционную иерархию, представляющую собой нечто статичное, вошедшее в плоть культуры и застывшее на уровне социальной онтологии [Bloch 1966; Nakane 1979; Ле Гофф 1992; Сергеев 1999], с другой - определенную систему, объединяющую атомарных индивидов (и принадлежащих традиционной иерархии, и стоящих вне ее) в некую иную структуру, параллельную традиционной. Здесь стоит особо подчеркнуть, что речь не идет о перманентном противостоянии данных структур; наоборот, они могут сосуществовать, и трансформация неформальной структуры в формальную - лишь один из возможных результатов их соприкосновений. Такой неформальной структурой являются социальные сети.

Под социальными сетями мы понимаем совокупность индивидов, обладающих распределенным, “децентрализованным” ресурсом; сам факт его “распределенности” препятствует образованию жесткой иерархии, место в которой определяется степенью приближенности к источнику ресурса [Прайс 1976; Habermas 1979]. Распределенный ресурс есть в известном смысле общая собственность; иными словами, индивид, получивший доступ к одной из “точек” сети, автоматически обретает потенциальную возможность доступа ко всем ресурсам, заключенным в данной сети. 
Топология социальных сетей весьма разнообразна [Garvey, Griffith 1967]. Некоторые сети существуют в рамках отдельных социальных, этнических или культурных групп (европейская аристократия в эпоху Модерна, цыганские общины, университетская элита и т.д.), другие пронизывают различные страты общества (любая сеть революционной организации в XIX - XX вв., иллюминаты во Франции в XVIII в. и др.). Они могут иметь и полицентричное, и звездообразное устройство (в последнем случае связи, ведущие к единому центру, проходят сквозь социальные страты, разрушая традиционную иерархию).

Нас сейчас интересует лишь одна разновидность социальных сетей - сеть интересного. Говоря о ней как о преломлении когнитивной системы интересного, мы тем самым характеризуем природу распределенного там ресурса, обладание которым и обуславливает принадлежность субъекта именно к данной сети. Этим ресурсом оказывается креативность [Гриффит, Миллер 1976].

Креативность есть способность создавать новое. Но интересное как таковое новым не является. Система интересного - это пространство когнитивной потенциальности. Каждый элемент подобной системы сам по себе является лишь единичным фактом, однако, будучи соединенными, они формируют потенциальную ситуацию для рождения нового знания - так же, как два семантически разноплановых понятия (тривиальные каждое по отдельности) в сочетании образуют нетривиальную метафору, способную дать толчок к осмыслению того, что ранее осмыслению не поддавалось, ибо не виделось возможности семантического совмещения.

Таким образом, система интересного объединяет в одной семантической плоскости разноплановые концепты, тогда как сеть интересного связывает носителей этих разноплановых концептов, дабы в момент их коммуникации возникло новое знание, а значит - и инновационный потенциал. Важно отметить, что речь идет именно об инновационном потенциале, а не о немедленной реализации инноваций. Сеть интересного, по определению, не может совпадать со структурой социальных иерархий, призванных охранять и передавать всю совокупность социокультурного опыта. Иерархия есть форма относительно статичная, сеть же - исключительно гибка и мобильна, поэтому возникшая в ее рамках инновация не может быть мгновенно усвоена иерархией и инкорпорирована в совокупный опыт. Тем не менее с течением времени или же под влиянием экстраординарных обстоятельств (когнитивный либо социальный кризис) это новое знание неизбежно приобщается к опыту культуры.

Если обратиться к европейской истории, то можно без труда обнаружить множество вариантов сетей интересного, иллюстрирующих различные аспекты функционирования рассматриваемой структуры. В эпоху позднего средневековья в Италии действовали сетевые образования, которые историки литературы условно называют “поэтическими кружками”. Наиболее известный пример - флорентийские “стильновисты”, к числу которых относился и Данте. Казалось бы, что любопытного в этих “кружках” для тех, кто изучает эволюцию социума? А интерес к ним должен быть большим, ибо выясняется, что образовывавшие их социальные субъекты внесли самый значительный инновационный вклад в развитие “своего” социума. Один лишь факт: текст “Божественной комедии” (а ее вклад в формирование социокультурного опыта общеизвестен), несмотря на свою очевидную эзотеричность и еретичность, при жизни автора обрел огромную популярность, а его создатель стал предметом чуть ли не преклонения; это свидетельствует о том, что субъекты той социальной сети, в которую был включен Данте, обладали колоссальным креативным чутьем. Известно, сколь широка была эта сеть; в нее входили как лица, пребывавшие на вершине иерархии (Кан Гранде делла Скала, Гвидо да Полента), так и фактические маргиналы (в частности, представители еврейской диаспоры Вероны) [Del Lungo 1881; Biscaro 1921; Carrara 1970; Bellomo 1990; Battistoni 1994, 1995, 1999]. В свою очередь, их социальная сеть охватывала крупнейших ученых и философов исламского Востока, а также ближайшее окружение многих мусульманских правителей. Иными словами, имелась сеть интересного, в одной точке которой находился вождь итальянских гибеллинов, в другой же - великий суфийский учитель из Дамаска. То обстоятельство, что мы плохо себе представляем масштабы и топографию сетей интересного, приводит к серьезной недооценке степени циркуляции когнитивных инноваций между политически и даже культурно враждебными социумами, а также между социумами, разделенными гигантскими расстояниями [Cerulli 1949; Levis 1970; Daniel 1975].

Сеть интересного в эпоху Ренессанса изучена достаточно хорошо [Symonds 1960; Венедиктов 1970; Burke 1974; Баткин 1978, 1989; Буркхардт 1996]. Удивительно высокая вертикальная мобильность того периода объяснялась тем, что в сеть интересного входили практически все социальные субъекты, стоявшие на вершине властной иерархии. С исключительно успешным функционированием данной сети связаны и аномальная креативность и разносторонность “титанов Возрождения”; благодаря включенности в сеть 
представителей высшего уровня властной иерархии произведенные там инновации смогли стремительно актуализироваться, автоматически пополняя совокупность признанного социокультурного опыта.

На заре эпохи Модерна происходит интеллектуальная глобализация Европы. Появление научных академий, стоявших выше государственных границ и политических пристрастий, позволяло быстро аккумулировать естественнонаучные знания, производимые по всему континенту. Именно в этом причина стремительного развития новых направлений науки, возникавших на стыке традиционных [Mandrou 1978; Debus 1983]. Наряду с научными академиями образовывались многочисленные академии “итальянского типа” своеобразные клубы интеллектуалов [Burke 1994]. Важнейшей чертой последних было преодоление в их стенах социальных барьеров. Так, участники заседаний знаменитой венецианской Accademia dell'Incogniti скрывали свои лица под масками, дабы влиятельные патриции, правившие республикой, своим статусом не смущали тех, кто захочет соревноваться с ними в эрудиции и остроумии [Battagia 1826].

Странными и немного зловещими примерами сетей интересного являются масонские общества и секты иллюминатов, развернувшие бурную деятельность перед Французской революцией и фактически подготовившие ее - если не в прямом, техническом смысле, то по крайней мере “когнитивно”, путем популяризации идей насильственного установления “царства Разума и Свободы”. Здесь мы видим ситуацию, когда субъекты сети интересного пытаются сознательно превратить ее в иерархию власти, сохранив при этом свой креативный, инновационный потенциал. Как показывает опыт, такая трансформация губительна не только для сети как структуры, но для ее субъектов. Тем не менее известны случаи относительно безболезненной трансформации сети интересного в иерархию власти, но лишь при условии значительной сложности сети, множественности ее субъектов и ограниченности территории, на которую распространяется власть получившийся из нее иерархии. В качестве примера можно привести карликовые средневековые исмаилитские государства [Бертельс 1959; Строева 1978; Daftari 1992].

Неизбежно возникает вопрос: в какие моменты “неформальный фактор”, т.е. сеть интересного, может подменить собой традиционные иерархические структуры, отвечающие за накопление и передачу знания? Тут прослеживаются два принципиальных сценария. В ситуации когнитивного кризиса традиционные социальные институты утрачивают легитимность, и вместе с ними теряет ценность весь накопленный социокультурный опыт вкупе с его хранителями. Естественным образом образовавшийся вакуум заполняется “параллельной” структурой, чьи субъекты оказываются в состоянии продуцировать когнитивные и социальные инновации, способствующие преодолению кризиса. В этом случае имеет место чистое замещение, результат которого может быть двояким: либо при стабилизации ситуации новая структура трансформируется в иерархию, чтобы через определенный промежуток времени цикл повторился, либо она делится — часть ее субъектов составляет иерархию, часть же вновь атомизируется, создавая затем сеть интересного.

Второй сценарий заключается в постепенном срастании сети с иерархией; что ведет к “омертвению”, окостенению сети, которая морфологически становится сходной с иерархией. Куновская теория развития науки, по большому счету, описывает именно такую ситуацию [Кун 1975], оставляя, однако, открытым вопрос о том, как в действительности происходит “нормализация” науки, т.е. “застывание” сети интересного и превращение ее в иерархию.

Оставляя этот непростой вопрос в стороне, обратим внимание на самую важную особенность сети интересного - на ее неуничтожимость_1]. На наш взгляд, причина такой неуничтожимости коренится в социальной необходимости сети интересного. Являясь резервом креативного потенциала социума, она не может прерваться, ибо в противном случае социум будет неминуемо уничтожен первым же кризисом: оставшись “один на один” с этим кризисом, социальные субъекты рискуют оказаться недостаточно креативными, чтобы его преодолеть. Креативность сети интересного можно уподобить единому разуму, мыслящему за всех тех, кто не в состоянии мыслить в ситуации, когда повергнуты сами основы, на которых строится постижение реальности.

Но насколько правомерно говорить (пусть даже метафорически) о некоем единстве разума, хотя бы в пределах очень узкой группы субъектов? Применительно к сообществу муравьев или пчел такое утверждение было бы вполне допустимым. Однако оно не лишено смысла и по отношению к социуму [Minsky 1988]. Процесс мышления не замыкается в рамках единичной рефлексии, все черпающей и всему научающейся, подобно Гераклиту, из самой себя. Как только индивидуальная рефлексия начинает опираться на идущее извне знание или вступает с ним в контакт, происходит столкновение единичной рефлексии с 
коллективным, распределенным знанием - опытом культуры. Если же мы возьмем все множество столкновений отдельных рефлексией с коллективным, “ничейным” знанием, рассредоточенным по всей сети интересного, то получим “распределенный разум”, работа которого возникает из накапливающихся единичных мыслительных актов.

В известном смысле можно утверждать, что далеко не все мыслительные акты индивидуальны, т.е. укоренены исключительно в сознании мыслящего субъекта. Существует совокупность инновационного знания, которое циркулирует в сети интересного, направляющей мысль единичного субъекта и обуславливающей ее форму. Другая разновидность единого распределенного разума - язык или онтология, которую разделяет группа людей [Манхейм 1994]. В пределах данной группы или языковой общности справедливо вести речь о распределенном разуме, который “мыслит индивидом”, уподобляясь единому и вечному разуму аверроистов [Шевкина 1972].

Там, где индивидуальный разум соприкасается с плодами усилий других разумов, возникает новая структура: единичность исчезает и образуется распределенное единство когнитивных возможностей субъектов сети. Этот тезис, в зачаточной форме звучащий уже у Сигера и ясно сформулированный Манхеймом на языке современной науки, не вносит смуту в наши представления о природе разума или инновационных процессов в обществе. Наоборот, перед нами открываются новые пути осмысления структур, образованных совокупностью когнитивных инновационных возможностей субъектов, включенных в сеть интересного. Рефлексия подобных сетевых структур, быть может, приблизит нас к пониманию той абсолютно неизвестной нам механики, которая движет инновационной деятельностью социальных субъектов и тем самым непрерывно трансформирует социум в соответствии с еще неясными для нас, но от этого не менее неумолимыми законами.

Баткин Л.М. 1978. Итальянские гуманисты: стиль жизни, стиль мышления. М.

Баткин Л.М. 1989. Итальянское Возрождение в поисках индивидуальности. М.

Бертельс А. 1959. Насири-и Хосров и исмаилизм. М.

Буркхардт Я. 1996. Культура Возрождения в Италии. М.

Васильев Л.С. 1972. Традиция и проблема социального прогресса в истории Китая. — Роль традиции в истории и культуре Китая. М.

Венедиктов А.И. 1970. Ренессанс в Римини. М.

Вертгеймер М. 1987. Продуктивное мышление. М.

Гербарт И.Ф. 1940. Избранные сочинения. М.

Голосовкер Я.Э. 1989. Интересное. — Вопросы философии, № 2.

Гриффит Б.Ч., Миллер А. Дж. 1976. Сети неформальной коммуникации среди продуктивных ученых. Коммуникация в современной науке. М.

Кассирер Э. 1990. Сила метафоры. - Теория метафоры. М.

Кузин Б.С. 1992. О принципе поля в биологии. — Вопросы философии, № 5.

Кули-Заде 3. 1970. Хуруфизм и его представители в Азербайджане. Баку.

Кун Т. 1975. Структура научных революций. М.

Ле Гофф Ж. 1992. Цивилизация средневекового Запада. М.

Манхейм К. 1994. Идеология и утопия. - Манхейм К. Диагноз нашего времени. М.

Песталоцци И.Г. Избранные педагогические сочинения. М. 
Прайс Д.Дж. 1976. Тенденции в развитии научной коммуникации — прошлое, настоящее, будущее. М. Руссо Ж.Ж. 1969. Рассуждение о науках и искусствах. — Руссо Ж.Ж. Трактаты. М.

Сергеев В.М. 1999. Демократия как переговорный процесс. М.

Сергеев К.В. 2002. Когнитивные модели и формирование религиозных институтов: античный протогностицизм. - Полис, № 5.

Строева Л.В. 1978. Государство исмаилитов в Иране в ХІ - XIII вв. М.

Филонов П.Н. 1923. Декларация Мирового Расцвета. — Жизнь искусства, № 20.

Фуко М. 1997. История безумия в классическую эпоху. СПб.

Фуко М. 2000. Надзирать и наказывать. М.

Халифман И.А. 1963. Пчелы. М.

Халифман И.А 1964. Муравьи. М.

Шовен Р. 1956. От пчелы до гориллы. М.

Шевкина Г.В. 1972. Сигер Брабантский и парижские аверроисты ХІІІ в. М.

Щуцкий Ю.К. 1993. Китайская классическая Книга Перемен. М.

Andrews A. 1962. The Greek Tyrants. L.

Battaglia V. 1826. Delle accademie veneziane. Venezia.

Battistoni G. 1994. Tramiti ebraici e fonti medievali accessibili a Dante, 1. Hilel ben Shemuel ben Eleazar di Verona. - Labyrinthos. Firenze, № 25/26.

Battistoni G. 1995. Tramiti ebraici e fonti medievali accessibili a Dante, 2. Manoello Giudeo. — Labyrinthos. Firenze, № 27/28.

Battistoni G. 1999. Tramiti ebraici e fonti medievali accessibili a Dante, 3. Dante nell "Paradiso" di Manoello Giudeo. — Labyrinthos. Firenze, № 35/36.

Bellomo S. 1990. Dante e le citta dell’esilio. — Italianistica, № 1.

Biscaro G. 1921. Dante a Ravenna. Roma.

Black M. 1962. Models and Metaphors. Studies in Language and Philosophy. Ithaca, L.

Bloch M. 1966. Feudal Society. Chicago.

Bonner A. (ed.) 1993. Doctor Illuminatus. A Ramon Llull Reader. Princeton.

Burke P. 1974. Tradition and Innovation in Renaissance Italy. L.

Burke P. 1994. Venice and Amsterdam. A Study of Seventeenth-Century Elites. Cambridge.

Carrara M. 1970. Dante nella civilta scaligera. Firenze.

Cerulli E. 1949. Il "Libro della Scala” e la questione delle fonti arabo-spagnole della "Divina Commedia”. Citta del Vaticano.

Daftari F. 1992. The Isma’ilis. Their History and Doctrines. Cambridge. 
Daniel N. 1975. The Arabs and Medieval Europe. L., Beirut.

Debus A.G. 1983. Man and Nature in the Renaissance. Cambridge.

Del Lungo I. 1881. Dell'esilio di Dante. Firenze.

Gadol J. 1969. Leon Battista Alberti. Universal Man of the Early Renaissance. L.

Garvey W.D., Griffith B.C. 1967. Scientific Communication as a Social System. — Science, vol. 157.

Giddens A. 1991. Modernity and Self-Identity. Self and Society in the Late Modern Age. Cambridge.

Habermas J. 1979. Communication and the Evolution of Society. Boston.

Habermas J. 1987. The Philosophical Discourse of Modernity. Cambridge.

Harrison J. 1989. Themis: a Study of the Social Origins of the Greek Religion. L.

Harrison J. 1991. Prolegomena to the Study of Greek Religion. Princeton.

Lakoff G., Johnson M. 1980. Metaphors We Live By. Chicago, L.

Levis A. 1970. The Islamic World and the West, AD 622 - 1492. N.Y.

Morris D. 1967. The Naked Ape. N.Y.

Mandrou R. 1978. From Humanism to Science 1480 — 1700. L.

Minsky M. 1988. The Society of Mind. N.Y., L.

Nakane C. 1979. Japanese Society. L.

North D., Thomas R. 1982. The Rise of the Western World. A New Economic History. Cambridge.

Osborne R. 1996. Greece in the Making, 1200 - 479 BC. L.

Salerno L. 1963. Salvator Rosa. Firenze.

Scholem G. 1969. On the Kabbalah and Its Symbolism. N.Y.

Sindona E. 191957. Paolo Uccello. Milano.

Symonds J. A. 1960. The Age of Despots. N.Y.

Tinbergen N. 1942. An objectivistic study of the innate behavior of animals. Leiden.

Tinbergen N. 1953. Social behaviour in animals, with special reference to vertebrates. L., N. Y.

Toulmin S. 1990. Cosmopolis. The Hidden Agenda of Modernity. N.Y.

Работа выполнена при поддержке РФФИ (грант № 020680039)

[1]Классический пример неуничтожимой сети — “гностическая традиция”, идущая с древнейших времен и не пресекшаяся и поныне [Сергеев 2002]. 